\title{
Residue Analysis of Pesticides, Herbicides, and Fungicides in Various Water Sources Using Gas Chromatography-Mass Detection
}

\author{
Mohammad Reza Samarghandi ${ }^{1}$, Mitra Mohammadi ${ }^{2}$, Amir Karami ${ }^{3,4}$, Leila \\ Tabandeh $^{2}$, Abdollah Dargahi ${ }^{3,4 *}$, Farhad Amirian ${ }^{5}$ \\ ${ }^{1}$ Department of Environmental Health Engineering, School of Public Health, Hamadan University \\ of Medical Sciences, Hamadan, Iran \\ ${ }^{2}$ Department of Environmental Health Engineering, School of Public Health, \\ Kermanshah University of Medical Sciences, Kermanshah, Iran \\ ${ }^{3}$ Student Research Committee, Hamadan University of Medical Sciences, Hamadan, Iran \\ ${ }^{4}$ Environmental Health Engineering, Faculty of Health, Hamadan University \\ of Medical Sciences, Hamadan, Iran \\ ${ }^{5}$ Department of Medicine, School of Medicine, Kermanshah University \\ of Medical Sciences, Kermanshah, Iran
}

Received: 10 January 2017

Accepted: 10 April 2017

\begin{abstract}
Pesticides along with with their degradation products spread throughout the environment and contaminate the water, leading to a consequent potential risk to humans and also the environment. The study aims to determinene the residual pesticides (organophosphorus, pyrethroids ), herbicides, and fungicides in the water resources (wells, deep wells, springs, spring-heads, and flumes) of Kermanshah Province, Iran. Water samples were taken from 50 stations from April to June 2016, and analyses were performed using gas-chromatography-mass-spectrometry techniques. Data were analysed using SPSS version 20. One of the most important points of this study is the fact that all water resources were safe except for deep wells. Total concentration of organophosphorus was $2.2 \mathrm{ppb}$. The mean concentration of pyrethroids in Islamabad Gharb and Songhor was 0.574 and 2.235 ppb, respectively. Organophosphorus and pyrethroid pesticides total concentration was more than the European standard. The contamination range of difenoconazole fungicide was $0.024 \mathrm{ppb}$ (Gilan Gharb) and $1.089 \mathrm{ppb}$ (Kermanshah). Glyphosate herbicide was only seen in Islamabad Gharb (0.011 ppb). The mean concentration of all pesticides in the investigated wells was more than the European standard. Estimating pesticide concentration is important for preserving aquatic ecosystems and human health.
\end{abstract}

Keywords: pesticides, herbicides, fungicides, water sources, Kermanshah

*e-mail: a.dargahi29@yahoo.com 


\section{Introduction}

Excessive use of pesticides in agriculture and the lack of attention toward environmental issues have resulted in environmental pollution as well as pollutants entering the food chain via water, air, and soil with considerable impact on agricultural ecosystems, groundwater sources, and so on [1]. Despite the advantages of pesticides, they are considered the most dangerous environmental pollutants. These pollutants not only are toxic, but also feature mobility and bio-accumulation properties. More importantly, these toxins could participate in various physical, chemical, and biological processes. Most of the pesticides have rigid conformation and persist widely in the environment [2]. Considering the physical and chemical properties of the pesticides and their high utilization in agriculture, the great extent of these pesticides were introduced into the surface and groundwaters.

Pesticides usually leach out from soil and plant surfaces and are introduced into lakes, rivers, and eventually into the seas, where they threaten aquatic life [3]. Waters from agricultural land drainage, wastewater, and pesticide-producing industries are indirect pesticide sources. Pesticides utilized for controlling various pests, including aquatic insects, are considered direct pollutants of the water [4-5]. Adverse health effects of pesticides include short-term impacts such as abdominal pain, dizziness, headache, double vision, nausea, and eye and skin problems, and the long-term complications include increased risk of respiratory problems, memory disorders, depression, neurological defects, cancer, and infertility [6-7]. In this regard, strict regulations were approved to control the levels of pesticide residues in the environment. According to the Drinking Water Quality Guidelines for Europe, the allowable concentration of pesticides is intended as 0.1 micrograms per litre for each of the toxic ones and 0.5 micrograms per litre for total pesticides. The U.S. Environmental Protection Agency (EPA) and the European Union (EU) have defined the highest herbicide amounts in potable water in the ppb range [8].

In the EU, the highest allowable amount for each herbicide is stated as $0.1 \mu \mathrm{g} / \mathrm{L}$ [9]. Having regard to the limited storage of fresh water in the world and the little contribution of groundwater as a potable water source, quality and quantity maintenance of these valuable sources at the optimum level is essential [10]. In order to make these sources safe, it is crucial that polluted sources be recognized rapidly and the pollution dissipation trend predicted and required operations done to prevent dispersion [11]. Regarding the environmental and health problems of pesticides and extensive utilization of the common pesticides in the productive lands of Kermanshah Province, Iran, and taking into account the fact that drinking water of Kermanshah city and suburban areas is supplied from groundwater sources, it is necessary to maintain the underground aquifers as the most important available and non-polluted sources of drinking water requiring no treatment. Therefore, monitoring these sources of drinking water in order to understand the pollution status is important.

\section{Materials and Methods}

Kermanshah Province is located at $34-35^{\prime} \mathrm{N}$ latitude and 46.3-47.3' W longitude within an area of $25,009 \mathrm{Km}^{2}$ in central Zagros, and consists of 14 urban areas [12]. Temperature in the studied area varies between 25 and $37^{\circ} \mathrm{C}$. Kermanshah is the agricultural center of Iran and its cities' incomes are mostly dependant on agriculture.

\section{Sampling and Sample Preparation}

Water samples from various drinking water sources (springs, springheads, wells, and aqueducts) were taken and kept in $2 \mathrm{~L}$ polyethylene bottles. Polyethylene bottles were initially rinsed by $\mathrm{HCl}$ and then rinsed with abundant water to wipe out $\mathrm{HCl}$ residues. Then the residuals were rinsed twice with distilled water and again filled with the main sample to the extent that there was some empty space left in the bottles. Bottles were sealed with wax and paraffin and the samples were kept in cold temperature and then transferred to the laboratory. Suspended materials in the water samples were filtered through a fluorine ethylene filter $(50 \times 0.45 \mathrm{~mm}$, Millipore, USA). Water samples were placed in glass bottles before extraction, which had already been rinsed and kept in $2-4^{\circ} \mathrm{C}$. Sampling was conducted in three-month intervals (April-June 2016) at each sampling site. Six samples were collected randomly from each sampling area with five-day intervals in the morning (08:00-10:00), in the afternoon (14:00-17:00), and in the evening (20:00-22:00), and the results were reported based on a ppb scale. The total number of samples was 900 .

\section{Chemicals}

Chloroform, dichloromethane, methanol, acetonitrile, $\mathrm{N}$-hexane, and other chemicals and reagents were purchased from Merck Co. (Germany) with high purity. Standard solutions, $1,000 \mu \mathrm{g} / \mathrm{mL}$ stock solution of oregano phosphorous, pyrethroid, and herbicide and fungicide standard toxins were prepared by weighing the specific toxins into $25-\mathrm{ml}$ volumetric flasks and then dissolving and diluting. All prepared solutions were filtered through $0.45 \mathrm{~m} \mu$ filters for gas-chromatography.

\section{Extraction Process}

Liquid-liquid extraction of pesticides residuals was conducted using the USEPA standard method. For pyrethroid extraction, initially $50 \mathrm{~mL}$ pyrethroid alongside with chloromethane (DCM) were poured into separator funnels containing $100 \mathrm{~mL}$ water and stirred for five minutes. Then the sample was kept stationary for 30 minutes for the perfect separation of the organic 
and the aqueous phases. Being separated, the organic phase was filtered into $250 \mathrm{~mL}$ volumetric flasks through anhydrous sodium sulfate $\left(\mathrm{Na}_{2} \mathrm{SO}_{4}\right)$, rinsed already using Dichloromethane.

\section{Extracted Sample Clearance}

Silica gel clean-up process was conducted based on the explained methods by Mensah et al. (2016) [19]. Clean-up was conducted using a packed propylene cartridge column with 1 gr silica gel that was kept in an oven at $130^{\circ} \mathrm{C}$ for $10 \mathrm{~h}$. Then, $20 \mathrm{~mL}$ DCM was utilized for column/cartridge rinsing. All samples were concentrated by Buchi Ratovapor R-210, USA at $40^{\circ} \mathrm{C}$. A residual sample was again dissolved in $1 \mathrm{ml}$ of ethylacetate and transferred into $2 \mathrm{ml}$ standard opening vials. The residual amount of pesticide was measured by gas-chromatography coupled with massspectrophotometry.

\section{Gas-Chromatography Conditions}

Gas chromatography conditions utilized in the present study (Hewlett-Packard 5890A) were as follows: gas pressure $60 \mathrm{psi}$, injection temperature $220^{\circ} \mathrm{C}$, column temperature $190^{\circ} \mathrm{C}$, detector temperature $270^{\circ} \mathrm{C}$, nitrogen gas velocity $30 \mathrm{~mL} / \mathrm{min}$, column length $200 \mathrm{~cm}$, internal diameter $2 \mathrm{~mm}$ ). In order to assure experimental accuracy, a control sample was analyzed and there was no peak. Then the samples were analyzed in the same way. A residual amount of the agricultural toxins was determined via standard procedures using peak regions. Measurements were conducted between detector linear range according to Afful (2013) and Frimpong et al. (2012) [7, 13]. Peak regions of residence times were analyzed simultaneously in comparison with the generalized standards to obtain the concentration on calibration curve. All glass flasks utilized in the experiments were rinsed with detergent and, on the second step, rinsed by laboratory distilled water and then dried at $150^{\circ} \mathrm{C}$. Afterward flasks were cooled and kept in dust-free shelves. All chemicals and reagents were checked so that there would not be any intervening material left. In the control samples there were no residual toxins. All samples were evaluated three times and the results were presented as means. In order to assure correlation coefficient of $\mathrm{R}^{2}=0.99$, calibration curve was conducted using consecutive samples. All experiments were conducted through instructions presented by Greulich et al. [14].

\section{Data Analysis}

To identify the significant differences among studied toxins based on the various drinking water sources, various cities, and distinct utilized toxins, the data were analysed using SPSS V. 20 throughout one-way analysis of variance at a significance level of 0.05 .

\section{Results and Discussion}

\author{
Pesticide Analysis
}

While utilizing these sources is unsafe and can harm consumers, according to our results, we found that water samples from springs and aqueducts in Kerend Gharb, Javanrood, Sarpolezahab, Salas Babajani, and Kermanshah had no detectable pollution (Table 1).

\section{Residual Pesticides in Water Resources of Kermanshah}

Following the aim of the study to evaluate the toxins separately in deep wells in Kermanshah Province, it should be noted that Paveh, Songhor, and Islam Abad Gharb had 0.015, 4.008, and $1.092 \mathrm{ppb}$ of permethrin, respectively. Also, phosphor odiazinon, chlorpyrifos and malathion pesticides were in the ranges of 0.143 (Kermanshah) to 2.683 (Songhor), 0.019 (Dalahoo) to 15.365 (Kermanshah), and 0.146 (Kermanshah) to 1.214 (Kermanshah). Also, pollution by fenvalerate and permethrin was respectively in the ranges of 0.016 (SarPole Zahab) to 1.002 (Kermanshah) and 0.015 (Paveh) to 1.092 (Islam Abad Gharb). The Highest and the lowest pollution were associated with the pyrotyroid toxin in Islam Abad Gharb and Snghor around 0.574 and $2.235 \mathrm{ppb}$. Generally, among the studied water sources the total amount of pyrotyroidi was less than one third of phosphorene insecticide. This could be due to more gardens and agricultural land and also higher applications of oregano phosphorene pesticide in Kermanshah Province. The total concentration of phosphorene toxins in well waters was $2.2 \mathrm{ppb}$. Average phosphorene toxin in deep wells of various cities was determined as follows: Paveh 0.027, Sahneh 3.178, Ravansar 1.999, Dalahu 0.386, Kangawar 3.626, Islam Abad Gharb 1.263, Songhor 2.176, GilanGharb 2.416, SarPole Zahab 2.71, Harsin 1.453, and Kermanshah $0.636 \mathrm{ppb}$. Also, the amounts of toxins in SarPole Zahab, Harsin, and Kermanshah were recorded as follows: 2.392, 1.048 , and $6.311 \mathrm{ppb}$, respectively.

Small words in Table 1 reveal the significant differences within pesticide residuals in the water sources and the cities. The diazinon amount in Paveh wells was not significantly different compared with other cities. So the amount of diazinon was lower than that of the others $(\mathrm{P}<0.05)$. Among deep wells of Ravansaar, Islam Abad Gharb, and Kermanshah, there was no significant difference $(\mathrm{P}<0.05)$. Chlorpyrifos mean that concentration in Kermanshah was more than in other cities, and in Paveh it was the lowest level. Chlorpyrifos in deep wells was significant within the cities $(\mathrm{P}<0.05)$. Malathion in Paveh wells was the lowest, so that malathion meant that the difference of Paveh with Sarpol Zahab, Harsin, and Kermanshah was meaningful $(\mathrm{P}<0.05)$. Furthermore, malathion in deep wells of Dalahoo was lower than in Harsin, Sarpol Zahab, 
Table 1. Residual pesticide in water sources of Kermanshah Province, Iran.

\begin{tabular}{|c|c|c|c|c|c|c|}
\hline \multirow{2}{*}{ City } & \multirow{2}{*}{ Water source } & \multicolumn{3}{|c|}{ Organo phosphorous pesticide residual, ppb } & \multicolumn{2}{|c|}{ Pyrethroid pesticide residual, $\mathrm{ppb}$} \\
\hline & & Diazinon & Chlorpyrifos & Malathion & Fenvalerate & Permethrin \\
\hline Paveh & Well & N.D ${ }^{a}$ & $0.082^{\mathrm{a}}$ & N.D ${ }^{a}$ & N.D ${ }^{a}$ & $0.015^{\mathrm{a}}$ \\
\hline Sahneh & Deep well & $1.409^{\mathrm{b}}$ & $7.79^{\mathrm{b}}$ & 0.335 & $0.69^{\mathrm{b}}$ & $\mathrm{ND}^{\mathrm{b}}$ \\
\hline Ravansar & Deep well & $0.441^{\mathrm{bc}}$ & $5.218^{\mathrm{b}}$ & 0.34 & 0.77 & $\mathrm{ND}^{\mathrm{b}}$ \\
\hline Kerend Gharb & Springhead & N.D & N.D & N.D & N.D & N.D ${ }^{b}$ \\
\hline Dalahoo & Deep well & $1.14^{\mathrm{b}}$ & $0.019^{\mathrm{b}}$ & N.D ${ }^{b}$ & $0.043^{\mathrm{b}}$ & $\mathrm{ND}^{\mathrm{b}}$ \\
\hline Kangavar & Deep well & $0.768^{\mathrm{b}}$ & $9.363^{\mathrm{b}}$ & $0.748^{\mathrm{b}}$ & $0.049^{b}$ & $\mathrm{ND}^{\mathrm{b}}$ \\
\hline $\begin{array}{l}\text { Islam Abad } \\
\text { Gharb }\end{array}$ & Deep well & $0.344^{\mathrm{bc}}$ & $3.104^{b}$ & 0.341 & $0.057^{\mathrm{b}}$ & $1.092^{\mathrm{b}}$ \\
\hline Songhor & Well & $2.683^{\mathrm{a}}$ & $3.846^{\mathrm{a}}$ & ND & $0.463^{\mathrm{a}}$ & $4.008^{\mathrm{a}}$ \\
\hline \multirow{3}{*}{ Javanrood } & Spring & N.D & N.D & N.D & N.D & N.D \\
\hline & Flume & N.D & N.D & N.D & N.D & N.D \\
\hline & Springhead & N.D & N.D & N.D & N.D & N.D \\
\hline \multirow{3}{*}{ Sarpolzohab } & Deep well & $1.112^{\mathrm{b}}$ & $3.013^{\mathrm{b}}$ & $1.005^{\mathrm{b}}$ & $0.016^{\mathrm{b}}$ & N.D ${ }^{b}$ \\
\hline & Springhead & N.D & N.D & N.D & N.D & N.D \\
\hline & Well & $1.003^{\mathrm{a}}$ & $5.15^{\mathrm{a}}$ & $1.023^{\mathrm{a}}$ & 0.089 & N.D ${ }^{a}$ \\
\hline \multirow{3}{*}{ Harsin } & Deep well & $1.096^{\mathrm{b}}$ & $2.25^{\mathrm{b}}$ & $1.013^{\mathrm{b}}$ & $0.035^{\mathrm{b}}$ & N.D ${ }^{b}$ \\
\hline & Springhead & ND & ND & ND & ND & N.D \\
\hline & Well & $1.009^{\mathrm{a}}$ & $1.132^{\mathrm{a}}$ & $1.005^{\mathrm{a}}$ & 0.017 & N.D ${ }^{a}$ \\
\hline \multirow{2}{*}{ Salas Babajani } & Springhead & N.D & N.D & N.D & N.D & N.D \\
\hline & Spring & N.D & N.D & N.D & N.D & N.D \\
\hline \multirow{2}{*}{ Gilan Gharb } & Springhead & N.D & N.D & N.D & N.D & N.D \\
\hline & Deep well & $1.222^{\mathrm{b}}$ & $5.025^{\mathrm{b}}$ & $1.003^{b}$ & $0.039^{b}$ & N.D ${ }^{b}$ \\
\hline \multirow{5}{*}{ Kermanshah } & Deep well & $0.143^{\mathrm{bc}}$ & $1.62^{b}$ & 0.146 & $0.039^{\mathrm{b}}$ & N.D ${ }^{b}$ \\
\hline & Well & $2.356^{\mathrm{a}}$ & $15.365^{\mathrm{a}}$ & $1.214^{\mathrm{a}}$ & $1.002^{\mathrm{a}}$ & N.D ${ }^{a}$ \\
\hline & Spring & N.D & N.D & N.D & N.D & N.D \\
\hline & Springhead & N.D & N.D & N.D & N.D & N.D \\
\hline & Flume & N.D & N.D & N.D & N.D & N.D \\
\hline
\end{tabular}

A similar word in any column means significant different statistically $(\mathrm{P}<0.05)$

Kangavar, and Gilan Gharb. Mean difference in the aspect of fenvalerate in the wells of Paveh and Kermanshah and Songhor was considerable $(\mathrm{P}<0.05)$. Fenvalerate in the deep wells of Sahneh was more than that of the other cities and, subsequentl, notable. Permethrin mean difference in the wells of Songhor was significant compared with other cities, so Permethrin in Songhor was the highest of all. In deep wells of Islam Abad Gharb the number was 1.092 , but in the other cities almost no detection was possible.

In Kerend Gharb, studied insecticide amounts were not detectable. According to the European Standard, total phosphorine and pyrotyroidtoxins was more than the allowable limit. Rahmanikhah et al. (2010) reported that phosphorine pesticide amount in surface waters, rivers, wells, springs, and ground waters from the Caspian Sea was $0.062,0.077,0.062,0.055$, and $0.059 \mathrm{ng} / \mathrm{L}$ [15]. In the present study, unlike Rahmanikhah et al. (2010) findings, toxin amounts in springs, groundwaters, and springheads were not detectable. Also, Singare (2016) studied phosphorine toxin residual in Mumbai river waters in India. Chlorpyrifos insecticide amount was $208.77 \mathrm{ng} / \mathrm{L}$, which was more than the standard amount [16]. Generally, studied insecticide amount in well waters was tractable, which possibly could be due to the high persistence of phosphorine and pyrotiroiud insecticides in the environment. Moreover, according to studies around the globe, the persistence of phosphorine in the water and 
Table 2. Residual herbicides and fungicides in water sources of Kermanshah Province, Iran.

\begin{tabular}{|c|c|c|c|c|}
\hline \multirow{2}{*}{ City } & \multirow{2}{*}{ Water source } & \multicolumn{2}{|c|}{ Herbicide residual, $\mathrm{ppb}$} & \multirow{2}{*}{$\frac{\text { Fungicide residual, } \mathrm{ppb}}{\text { Difenoconazole }}$} \\
\hline & & Butachlor & Glyphosate & \\
\hline Paveh & Well & N.D & N.D & N.D \\
\hline Sahneh & Deep well & 0.024 & N.D & $0.069^{\mathrm{b}}$ \\
\hline Ravansar & Deep well & N.D & N.D & $0.105^{b}$ \\
\hline Kerend Gharb & Springhead & N.D & N.D & N.D \\
\hline Dalahoo & Deep well & N.D & N.D & $0.085^{b}$ \\
\hline Kangavar & Deep well & N.D & N.D & $0.42^{\mathrm{b}}$ \\
\hline Islam Abad Gharb & Deep well & N.D & 0.011 & $0.386^{\mathrm{b}}$ \\
\hline Songhor & Well & N.D & N.D & $0.346^{\mathrm{a}}$ \\
\hline \multirow{3}{*}{ Javanrood } & Spring & N.D & N.D & N.D \\
\hline & Flume & N.D & N.D & N.D \\
\hline & Springhead & N.D & N.D & N.D \\
\hline \multirow{3}{*}{ Sarpolzahab } & Deep well & N.D & N.D & $0.125^{b}$ \\
\hline & Springhead & N.D & N.D & N.D \\
\hline & Well & N.D & N.D & $0.099^{\mathrm{a}}$ \\
\hline \multirow{3}{*}{ Harsin } & Deep well & N.D & N.D & $0.101^{\mathrm{b}}$ \\
\hline & Springhead & N.D & N.D & ND \\
\hline & Well & N.D & N.D & $0.055^{\mathrm{a}}$ \\
\hline \multirow{2}{*}{ Salas Babajani } & Springhead & N.D & N.D & N.D \\
\hline & Spring & N.D & N.D & N.D \\
\hline \multirow{2}{*}{ Gilan Gharb } & Springhead & 0.005 & N.D & N.D \\
\hline & Deep well & 0.031 & N.D & $0.024^{\mathrm{b}}$ \\
\hline \multirow{5}{*}{ Kermanshah } & Deep well & N.D & N.D & $0.035^{\mathrm{b}}$ \\
\hline & Well & N.D & N.D & $1.089^{\mathrm{a}}$ \\
\hline & Spring & N.D & N.D & N.D \\
\hline & Springhead & N.D & N.D & N.D \\
\hline & Flume & N.D & N.D & N.D \\
\hline
\end{tabular}

A similar word in any column means significant different statistically $(\mathrm{P}<0.05)$

environment is high [17]. On the whole, previous studies have shown that the physical and chemical structures of these compounds and their stability in the alkaline medium cause their persistence [18]. Considering the presence of phosphorine and pyrotiroid toxins in the concentrated water samples from the studied wells, there would be the possibility of leakage of toxins into drinking water sources, increasing their concentrations in the future. So proper strategies for protecting these sources should be applied. Residual toxin amounts in agricultural water sources in Kermanshah Province, compared with other similar studied areas, was higher. Reasons could be the higher and unprincipled application, lower awareness, and also lack of sufficient education among the farmers for the proper toxin application.

\section{Herbicide and Fungicide Analysis}

According to the results, it should be noted that butachlor herbicide was only observed in the deep well waters in Sahneh and Guilan Gharb towns at 0.024 and 0.031-0.005 ppb, respectively. In other samples there was no pollution (Table 2 ).

\section{Residual Herbicides and Fungicides in Water Resources of Kermanshah}

In regard with glyphosate, it should be noted that only in Islam Abad Gharb were there pollution signs in deep wells, but in other cities there was no threat regarding health issues. Difenoconazole fungicide amount 
varied from $0.024 \mathrm{ppb}$ in Guilan Gharb to $1.089 \mathrm{ppb}$ in Kermanshah. Reported mean concentration of fenvalerate in Sar Pole Zahab, Songhor, Islam Abad Gharb, Kermanshah, Sahneh, and Ravansarin in the present study was higher than the $0.0086 \mathrm{ppb}$ reported in Afful et al. (2013) and Fosu-Mensah (2016) studies in Ghana water samples [13, 19]. According to the European standards, insecticide amounts in cities in Kermanshah Province were lower than the allowable standards, while difenoconazole fungicide in Kangawar, Islam Abad Gharb, Songhor, and Sarpol Zahab was higher than the allowable standard [8]. Total herbicide amounts in all of the studied cities was lower than the allowable standard on WHO.

As obvious as it is in Table 2, butachlor and glyphosate residuals have no significant mean differences after accounting for the type of water source and the city $(\mathrm{P}>0.05)$. Difenoconazole residual in the wells of Kermanshah was more than that of Songhor, Sarpol Zahab, and Harsin $(\mathrm{P}<0.05)$. The amount of this herbicide in the deep wells of Kangavar and Islam Abad Gharb experienced no significant mean differences compared with the rest of the cities $(\mathrm{P}>0.05)$. In other words, water sources in these cities were recognized as safe in terms of these toxins. The presence of toxins in the present study comes from the fact that phosphorine and pyrotiroid insecticides have been utilized for decades in Kermanshah Province, and there have been no specific criterion and monitoring. Although surface water sources had no toxins, there is the possibility of being polluted due to bioaccumulation of the agricultural toxins in the sediments of sampling areas and their leakage into water through residuals of agricultural toxins [20]. According to the studies it was recognized that toxins that were more utilized by farmers are of the phosphorine and pyrotyrod types. Meanwhile, the amounts of herbicides and fungicides applied by local farmers is low. The presence of toxins in the concentrated water samples indicates the leakage of toxins into drinking water sources, leading to ever-increasing risk of pollution in these sources. Numerous studies worldwide show that organo phosphorine toxins usually are the pollutant source for the drinking water, particularly in rural and urban areas, agricultural lands, and citrus orchards. According to the results based on the one-way analysis of variance, difference in mean concentration of studied toxins was significant in terms of water-supplying sources. Thus, surface waters had no pollution while groundwaters had significantly higher toxin amounts $(\mathrm{P}<0.05)$.

According to results of the analysis of variance, mean concentration of phosphorine toxins was significant in various cities. In order to find the cities with significant differences we conducted a Duncan tracing test. Using Duncan at a $5 \%$ probability level we found that the mean concentration of phosphorine toxins in all cities had significant differences $(\mathrm{P}<0.05)$. In regard with Pyrotyroid toxins it should be noted that there were significant differences between Islam Abad Gharb and Songhor and other urban areas in terms of the studied toxins
$(\mathrm{P}<0.05)$. Also, in terms of the toxin type, we found that chloropyriphus content in Kerend, Dalahu, Salas, and Pave had no significant difference $(\mathrm{P}<0.05)$. During the analysis of diazinon, conducting Dunnet T3 test in various cities, it was implied that there was significant difference between Kermanshah, Songhor, Sarpol Zahab, and GuilanGharb, while Harsin had no significant difference with other cities $(\mathrm{P}<0.05)$.

There was significant difference in malathion toxin between Kangawar and other cities, including Paveh, Kerned Gharb, Dalahu, Sonnghor, and Salas Babajani $(\mathrm{P}<0.05)$. In the present study, regarding the high mean precipitation rate in Kermanshah area and not using modern irrigation methods, precipitation and improper irrigation could be the reason for pesticides displacing into these sources. Considering the toxin-spraying months in April and June, besides the fact that most of the farmers spend time in gardens during this time, having contact with water sources and sometimes even consuming these waters, it is recommended that for at least one month or for assurance - up to two months, it is best to avoid using the utilized water for household consumption, or at least boiling the water to the point of toxin degradation at high temperature given the pesticides traits.

Generally, the pollution rate in some cases was more than the allowable range, indicating lack of awareness among farmers and also the producers about how and when to apply these toxins, and also ignoring the issues that could be brought up through offering polluted products in society and among the individuals. Therefore, improving farmer knowledge about utilizing pesticides for each product, application dosage, and utilization frequency to reduce the risk of pesticide intake by society is highly recommended [21]. On the other hand, consecutive and precise supervision by experienced experts on toxin utilization and pesticide types is essential [22].

\section{Conclusion}

Agricultural toxin pollution results from environmental factors like leakage, runoff, and excessive use of toxins in water sources is observed in toxin-utilizing areas. This pollution could have a destructive impact on human health. The present study showed that studied surface water samples had no agricultural toxins and were recognized as safe for household consumption. Successive supervision on well waters is required to retain the water quality and prevent environmental pollution.

\section{Acknowledgements}

This research was supported by the Hamadan University of Medical Sciences (No. 9504292456). We acknowledge the research and technology deputy of the university for the financial aid provided for the study. 


\section{References}

1. ARIAN M., ARAM Z. Relative Tectonic Activity Classification In The Kermanshah Area, Western Iran. Solid Earth. 5, 1277, 2014.

2. BAKORE N., JOHN P., BHATNAGAR P. Organochlorine Pesticide Residues In Wheat And Drinking Water Samples From Jaipur, Rajasthan, India. Environmental Monitoring And Assessment. 98, 381, 2004.

3. CAMPO J., MASIA A., BLASCO C., PICO Y. Occurrence And Removal Efficiency Of Pesticides In Sewage Treatment Plants Of Four Mediterranean River Basins. Journal Of Hazardous Materials. 263, 146, 2013.

4. CCANCCAPAA., MASIAA., ANDREU V., PICO Y. SpatioTemporal Patterns Of Pesticide Residues In The Turia And Júcar Rivers (Spain). Science Of The Total Environment. 540, 200, 2016.

5. PIRSAHEB M., DARGAHI A., HAZRATI S., FAZLZADEDAVIL M. Removal Of Diazinon And 2, 4-Dichlorophenoxyacetic Acid (2, 4-D) From Aqueous Solutions By Granular-Activated Carbon. Desalination And Water Treatment. 52, 4350, 2014.

6. CLARKE E., ADERINOLA O., ADEBOYEJO O. Persistent Organochlorine Pesticides (POPs) In Water, Sediment, Fin Fish (Sarotherodon Goalies) And Shell Fishes. Callinectes Pallidus And Macrobrachium Macrobrachium. 59, 122, 2013.

7. FRIMPON K., YEBOAH P., FLETVHER J., ADOMAKO D., PWAMANG J. Assessment Of Organochlorine Pesticides Residues In Cocoa Beans From Ghana. Elixir Food Sci. 50, 10257, 2012.

8. USEPA U., Environmental Protection Agency. Urban Air Toxics Monitoring Program (UATMP). Office Of Air Quality Planning and Standards, Research Triangle Park, NC. 1992, 27711, 2004.

9. WU Y., LEE H., LI S. High-Performance Chiral Separation Of Fourteen Triazole Fungicides By Sulfated $\beta$-Cyclodextrin-Mediated Capillary Electrophoresis. Journal Of Chromatography A. 912, 179, 2001.

10. DARGAHI A., GOLESTANFAR h., DARVISHI P., KARAMI A., HASAN S. H., POORMOHAMMADI A., BEHZADNIA A. An Investigation And Comparison Of Removing Heavy Metals (Lead And Chromium) From Aqueous Solutions Using Magnesium Oxide Nanoparticles. Pol. J. Environ. Stud. 25, 557, 2016.

11. ISMAIL A., DERBALAH A., SHAEEN S. Monitoring And Re-mediation Technologies Of Organochlorine Pesticides In Drainage Water. Polish Journal Of Chemical Technology. 17, $115,2015$.
12. LAHAFIAN J. The Newly Found Petroglyphs In the Western Kermanshah. In Arts, Multidisciplinary Digital Publishing Institute, 24, 78, 2015.

13. GREULICH K., ALDER L. Fast Multi-Residue Screening Of 300 Pesticides In Water For Human Consumption By LCMS/MS. Analytical And Bioanalytical Chemistry. 391, 183, 2008.

14. RAHMANIKAH Z., SARI A.E., BAHRAMIFAR N., BOUSJIEN Z.S. Organophosphorous Pesticide Rresidues in the Surface and Ground Water in The Southern Coast Watershed Of Caspian Sea, Iran. World Applied Sciences Journal. 9, 160, 2010.

15. SINGARE P.U. Distribution And Risk Assessment Of Suspected Endocrine-Disrupting Pesticides In Creek Water Of Mumbai, India. Marine Pollution Bulletin. 102, 72, 2016.

16. SU Y.S., JEN J.F. Determination Of Organophosphorous Pesticides In Water Using In-Syringe Ultrasound-Assisted Emulsification And Gas Chromatography With ElectronCapture Detection. Journal of Chromatography A. 1217, 5043, 2010.

17. BONDARENKO S., GAN J., HAVER D.L., KABASHIMA J.N. Persistence Of Selected Organophosphate And Carbamate Insecticides In Waters From a Coastal Watershed. Environmental Toxicology and Chemistry. 23, 2649, 2004.

18. AFFUL S., WUDZA J.A., OSAE S., TWUMASI, S.K. Assessment Of Synthetic Pyrethroids Residues In The Waters And Sediments From The Weija Lake In Ghana. 2013.

19. FOSU- MENSAH B.Y., OKOFFO E.D., MENSAH M. Synthetic Pyrethroids Pesticide Residues in Soils and Drinking Water Sources from Cocoa Farms in Ghana. Environment and Pollution. 5, 60, 2016.

20. FILLATRE Y., RONDEAU D., DAGUIN A., COMMUNAL P.Y. A Work-Flow For Multiclass Determination Of 256 Pesticides In Essential Oils By Liquid Chromatography Tandem Mass Spectrometry Using Evaporation And Dilution Approaches: Application To Lavandin, Lemon And Cypress Essential Oils. Atlanta. 149, 178, 2016.

21. SHOKRZADEH M., SAEEEDI SAREVI S. Measurement Of Residues Of Benomyl And Mancozeb Pesticides In Shrub And Nonshrub Cucumbers Sampled From Different Regions Of Mazandaran Province (Iran). Toxicological \& Environmental Chemistry. 91, 627, 2009.

22. RODRIGUEZ-MOZAZ S., RICART M., KOCKSCHULMEYER M., GUASCH H., BONNINEAU C., PROIA L., DE ALDA M.L., SABATER S., BARCELO D. Pharmaceuticals And Pesticides In Reclaimed Water: Efficiency Assessment Of a Microfiltration-Reverse Osmosis (MF-RO) Pilot Plant. Journal Of Hazardous Materials. 282, 165, 2015. 